\title{
NATIONAL CENTER FOR GEOGRAPHIC INFORMATION AND ANALYSIS
}

(NCGIA)

The U.S. National Center for Geographic Information and Analysis was established in 1988 at the University of California, Santa Barbara; the State University of New York at Buffalo (the University at Buffalo); and the University of Maine. Funded from 1988 through 1996 by the National Science Foundation (NSF) following an open competition, the center continues under a collaborative agreement between the three institutions. The center's mission is to conduct research in geographic information science, and to undertake associated educational and outreach programs.

By 1986 it had become clear that geographic information systems (GIS) were a growing computer application with abundant uses in a range of human activities, including science. At NSF the officer newly responsible for the Geography and Regional Science program, Ron Abler, saw an opportunity to promote the establishment of a research center that would act as a focus for research and education in this new field. A solicitation was developed that suggested five themes for research: spatial analysis and spatial statistics; spatial relationships and database structures; artificial intelligence and expert systems; visualization; and social, economic, and institutional issues. Eight teams responded to the solicitation issued by NSF in early 1987, and the project was awarded to the three-site consortium led by UC Santa Barbara.

Two key activities immediately served to characterize the new center and its proposal. First, research was to be conducted as a series of Initiatives, each one lasting from two to three years and focusing on a specific topic within the five major themes. 
Each Initiative would begin with a Specialist Meeting that would bring 20-40 scholars together to review the state of the art and develop and prioritize a research agenda. The Initiative would proceed through activities both inside the center and in the broader community, and would end with presentations on research results at a major conference and a final report. The first Specialist Meeting was held in December 1988 on the subject of the Accuracy of Spatial Databases, and to date over 40 topics have been investigated. The second activity was developed in response to a perceived lack of textbooks and other teaching materials in the growing field of GIS education. A Core Curriculum was designed as a collection of 75 sets of prototype lecture notes, and authors were recruited to prepare drafts. During the 1989-1990 academic year roughly 100 instructors agreed to teach part or all of the curriculum, and their experiences were used to prepare a final draft that was published in 1990. Over 1500 copies of the curriculum, assembled in three large binders, were distributed in the following years, and became a foundation for the rapid expansion of worldwide education in GIS.

\section{REFERENCES}

Abler, R. F. (1987). The National Science Foundation Center for Geographic Information and Analysis. International Journal of Geographical Information Systems, 1, 303-326. DiBiase, D., DeMers, M., Johnson, A., Kemp, K., Luck, A. T., Plewe, B., \& Wentz, E. (Eds.) (2006). Geographic Information Science \& Technology Body of Knowledge. Washington, DC: Association of American Geographers.

\section{CROSS-REFERENCES}


Egenhofer, Max

Frank, Andrew

Geographic Information Systems

GIScience

Goodchild, Michael

Mark, David

Michael F. Goodchild 